\title{
COVID-19-Associated Hyper-Fibrinolysis: Mechanism and Implementations
}

\author{
Giris Jacob ${ }^{1,2 *}$, Anat Aharon ${ }^{2}$ and Benjamin Brenner ${ }^{3}$ \\ ${ }^{1}$ Medicine F and Recanati Research Center, Tel Aviv Medical Center, Sackler Faculty of Medicine, Tel Aviv University, Tel Aviv, \\ Israel, ${ }^{2}$ Hematologic Research Laboratory, Hematologic Department, Tel Aviv Medical Center, Sackler Faculty of Medicine, \\ Tel Aviv University, Tel Aviv, Israel, ${ }^{3}$ Coagulation Research Laboratory Unit, Department of Hematology, Rambam Medical \\ Center, Rappaport Faculty of Medicine, Technion - Israel Institute of Technology, Haifa, Israel
}

\section{OPEN ACCESS}

Edited by:

Georges Leftheriotis,

Université Côte d'Azur, France

Reviewed by:

Shisan (Bob) Bao,

The University of Sydney, Australia

Denis Doyen,

University of Nice Sophia Antipolis,

France

${ }^{*}$ Correspondence:

Giris Jacob

jacobgi@t/vmc.gov.il

Specialty section:

This article was submitted to Integrative Physiology,

a section of the journal

Frontiers in Physiology

Received: 18 August 2020 Accepted: 24 November 2020 Published: 16 December 2020

Citation:

Jacob G, Aharon A and Brenner B (2020) COVID-19-Associated Hyper-Fibrinolysis: Mechanism and Implementations.

Front. Physiol. 11:596057. doi: 10.3389/fphys.2020.596057
The emerging novel coronavirus disease (COVID-19), which is caused by the SARSCoV-2 presents with high infectivity, morbidity and mortality. It presenting a need for immediate understanding of its pathogenicity. Inflammation and coagulation systems are over-activated in COVID-19. SARS-CoV-2 damages endothelial cell and pneumocyte, resulting in hemostatic disorder and ARDS. An influential biomarkers of poor outcome in COVID-19 are high circulating cytokines and D-dimer level. This latter is due to hyperfibrinolysis and hyper-coagulation. Plasmin is a key player in fibrinolysis and is involved in the cleavage of many viruses envelop proteins, including SARS-CoV. This function is similar to that of TMPRSS2, which underpins the entry of viruses into the host cell. In addition, plasmin is involved in the pathophysiology of ARDS in SARS and promotes secretion of cytokine, such as IL-6 and TNF, from activated macrophages. Here, we suggest an out-of-the-box treatment for alleviating fibrinolysis and the ARDS of COVID19 patients. This proposed treatment is concomitant administration of an anti-fibrinolytic drug and the anticoagulant.

Keywords: SARS-CoV-2, COVID-19, fibrinolysis, coagulation, tranexamic acid

\section{INTRODUCTION}

The emerging novel coronavirus disease (COVID-19), which is caused by the SARS-CoV-2, presents with high infectivity, morbidity, and mortality. The pressing need for understanding the virus' pathogenicity and its interaction with the body's biologic defense systems are required ( $\mathrm{Li}$ et al., 2020). The inflammatory response and the coagulation system frequently join forces to build an effective defense against an assaulting pathogen (Arneth, 2019). Interactions between these two systems offer potential opportunities for novel therapeutic modalities. Unusually high circulating D-dimer (DDI) levels are a main predictor of poor outcome, and indicate that the coagulation and fibrinolytic systems are overactive in COVID-19 (Tang et al., 2020b; Zhou et al., 2020). This review highlights the relationship between virus infectivity and the fibrinolytic system, and suggests a potential new therapeutic modality to mitigate the virus' infectivity in COVID-19.

\section{Etiologic-Pathogenicity of COVID-19}

SARS-CoV-2 is a RNA beta-coronavirus of zoonotic origin, and is closely related to the SARS-CoV and MERS-CoV, according to whole genome sequencing (Shirato et al., 2020; Zhou et al., 2020). 
The virus is highly infective and respiratory droplets are the main route of its transmission between humans (Ong et al., 2020).

The basic pathogenesis of COVID-19 shares common characteristics with that of SARS and MERS. From a clinical perspective, the airways and lungs are the most affected organs (Pan et al., 2020). Autopsies of COVID-19 patients reveal that the vascular bed is also severely affected (Fox et al., 2020). This specific tropism of SARS-CoV-2 for epithelial cells of the lungs and vascular systems could explain its infectivity.

The spike protein on the surface of the glycoprotein envelope of SARS-CoV-2 comprises two domains: a receptorbinding domain (S1), which binds with high affinity to the angiotensin-converting enzyme 2 (ACE2) receptor on the membranes of human pneumocytes and vascular endothelial cells, (Hamming et al., 2004; Whittaker and Millet, 2020; Zhang et al., 2020) and an S2 domain for anchoring the virus on target host cell membrane (Coutard et al., 2020). Based on homology to SARS-CoV, it has been reported that SARS-CoV2 requires a host cell protease to achieve infectivity and spread (Hoffmann et al., 2020). After binding to the ACE2 receptor, the S2 protein is proteolytically activated by transmembrane serine protease 2 (TMPRSS2) in order to enter the host cell (Matsuyama et al., 2020).

COVID-19 presents with a wide spectrum of clinical severity, which ranges from a mild pneumonia to a severe disease that could result in acute respiratory distress syndrome diseaselike (ARDS) (Guan et al., 2020; Wu and McGoogan, 2020). The ARDS-like feature in COVID-19 is notably different from that seen in septic patients (Yang et al., 2020). The main clinical laboratory findings associated with a poor outcome are lymphopenia, abnormal liver function test, raised serum levels of ferritin and C-reactive protein, and DDI (Shi et al., 2020; Wu et al., 2020; Zhou et al., 2020). High plasma DDI level is consistently advocated as a major predictor of mortality, which suggests that abnormal coagulation plays a key role the pathogenesis of COVID-19 (Chen et al., 2020; Grasselli et al., 2020; Tang et al., 2020a,b; Wang D. et al., 2020).

\section{COAGULATION AND FIBRINOLYSIS: (SEE FIGURE 1)}

The extrinsic pathway is triggered by tissue injury, which increases endothelial expression of activated tissue factor (aTF), which in turn activates FVII and the subsequent activation of FX, and formation of the aTF-FVIIa-FXa complex. This complex and the generated thrombin possess the ability to induce intracellular pro-inflammatory signaling via protease-activated receptor 1 and 2 (PAR 1 and 2) (Montagnana et al., 2017). On the other hand, the protein $\mathrm{C}$ complex, which comprises thrombin-thrombomodulin and activated protein $\mathrm{C}$, deactivates FVIIIa and FVa (acceleration factors), and results in deceleration of the coagulation process (Vatsyayan et al., 2014; Yau et al., 2015). This anti-coagulation pathway (protein C complex) requires an intact vascular endothelium, which expresses the endothelial cell protein C receptor (EPCR) (Palta et al., 2014;
Swieringa et al., 2018). A damaged endothelium frees EPCR (soluble EPCR), which avidly binds to the free activated protein $\mathrm{C}$ complex and loss of its anticoagulant moiety, promotes hypercoagulability (Ducros et al., 2012). In addition, the EPCRProtein C complex exerts a cytoprotective effect under normal conditions (Zelaya et al., 2018). This complex activates PAR1 signaling to generate anti-inflammatory and anti-apoptotic effects (Mosnier et al., 2007; Mohan Rao et al., 2014).

The activated fibrinolytic system on endothelial cells is crucial for dissolving the fibrin clot and facilitating tissue repair. Plasmin, a serine protease, is the key-player in this system and is responsible for degrading fibrin (Olson, 2015; Iba and Levy, 2018).

\section{COVID-19 AND COAGULATION-FIBRINOLYSIS DYSFUNCTION}

Reports on patients with COVID-19 emphasize the presence of increased thrombosis and fibrinolysis and less bleeding diathesis (Huang et al., 2020; Tang et al., 2020b). An atypical disseminated intravascular coagulation (DIC) is also seen in COVID-19 (Klok et al., 2020) as thrombocytopenia, hypofibrinogemia, hemolytic anemia, and bleeding are under-represented (Fox et al., 2020; Han et al., 2020; Tang et al., 2020b). Of all the features, the most prominent prognostic factor in patients with COVID-19 is the high plasma DDI levels (Iba et al., 2017; Tang et al., 2020b; Zhou et al., 2020).

Recent clinical observations provide evidence that COVID-19 patients are at high VTE and mortality risks, and anticoagulant therapy might improve their prognosis (Paranjpe et al., 2020; Song et al., 2020; Tang et al., 2020a; Wu et al., 2020; Yin et al., 2020). General agreement exists on the need for thromboprophylaxis in majority of COVID-19 patients, and some suggest that this treatment should be continued after hospital discharge (Kollias et al., 2020).

Coagulation abnormalities include a prolonged prothrombin time, low antithrombin activity, and increased fibrinogen and DDI levels. However, the mechanisms of abnormal coagulation and fibrinolysis in COVID-19 patients are unknown (Han et al., 2020; Tang et al., 2020b).

The finding of a very high plasma DDI level is a hallmark for hyper-fibrinolysis in COVID-19. The strong association between high plasma DDI levels and the poor outcome raises several thoughts. Anticoagulation therapy barely reduces mortality, except in a small subgroup of patients, whose plasma DDI levels were six times greater than normal levels (Tang et al., 2020b). Alteplase is a fibrinolytic agent and when administered to patients with COVID-19-related ARDS, all died despite improvements in their oxygenation indices (Wang J. et al., 2020). This treatment was based on the results of animal studies which found that fibrinolytic drugs might improve lung function and alleviate inflammation in ARDS-like animal models (Hardaway et al., 1990; Liu et al., 2018). The present evidence does not support the use of fibrinolytic drugs in COVID-19 patients with ARDS. We can deduce that hyper-fibrinolysis 


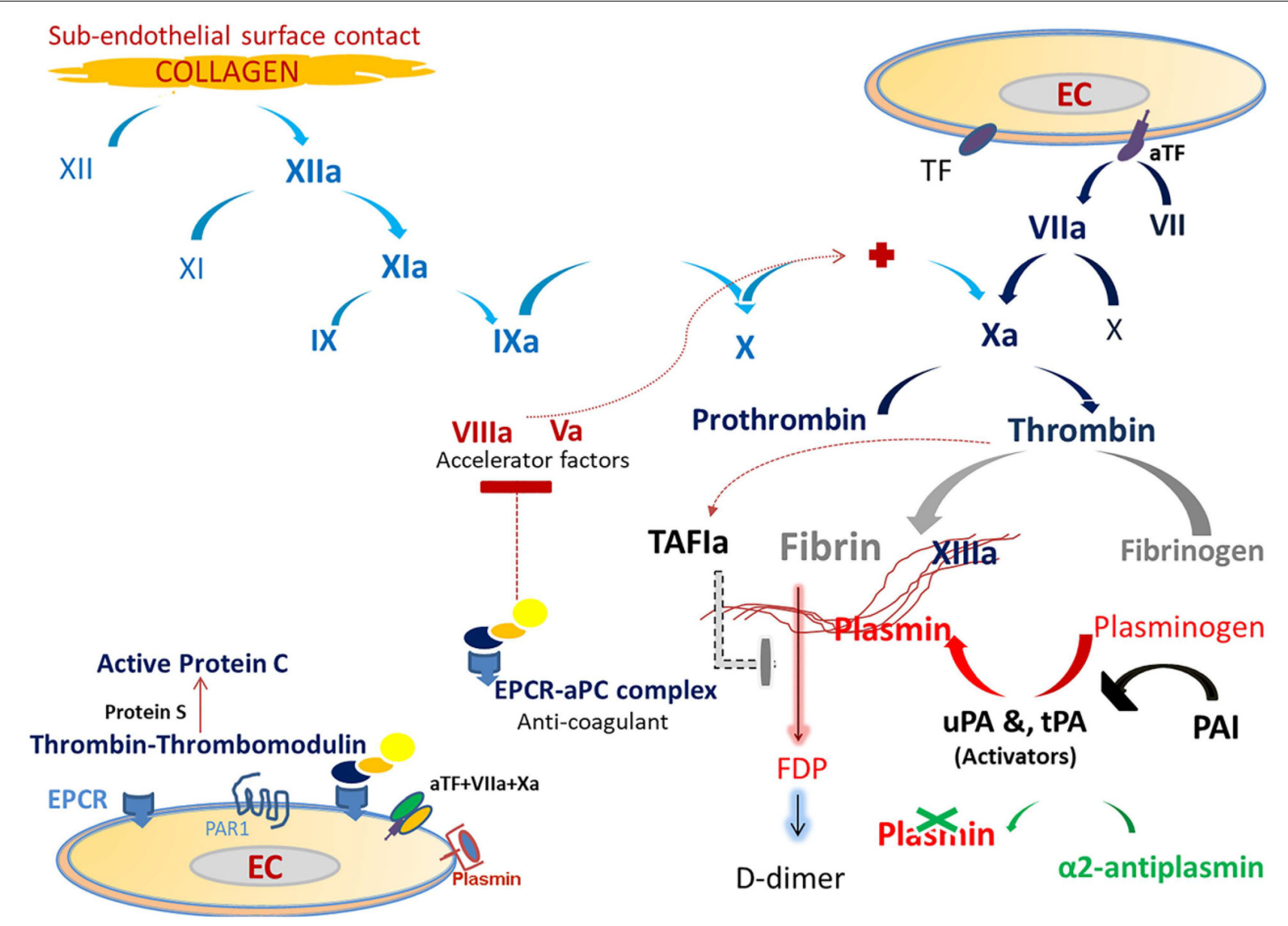

FIGURE 1 | The figure displays the coagulation and fibrinolysis processes. Traditionally, the extrinsic pathway of the main coagulation cascade depends on the release of tissue factor (TF). Injured endothelial cells (EC) by any cause results in increased expression of TF in the cell membrane. This increased expression activates FVII, which then results in TF-FVIla binding and activating FX. FX is also activated via the intrinsic pathway (collagen path). TF-FVII-FXa is the coagulation initiation complex which binds to EC and stimulates the generation of thrombin from prothrombin. Thrombin triggers many processes, which include fibrin generation, FXIII activation, and activation of protein C. FXIIla polymerizes fibrin to form the final stable clot. Thrombin binds to the endothelial Protein C receptor (EPCR) and combines with thrombomodulin to activate protein C (aPC) and generate the EPCR-aPC complex. This complex has anti-coagulation activity by blocking the procoagulant factors, FVa and FVIIla (accelerator factors) and a cytoprotective effect via the protease-activated receptor 1 (PAR1). Fibrinolysis (clot solubilization) is triggered in the presence of fibrin. The conversion of circulating zymogen plasminogen to plasmin is done by endothelial enzymes and the tissue and urokinase plasminogen activators (tPA and UPA, respectively). Plasmin, a key player in fibrinolysis, is a serine protease which cleaves fibrin to generate fibrin degradation products (FDP). Plasminogen activator-inhibitor (PAI) blocks both tPA and UPA. The main plasmin inhibitor is $\alpha 2$-antiplasmin, which is a potent free plasmin (not bounded to fibrin) scavenger. In addition, TAFI (thrombin-activatable fibrinolysis inhibitor) attenuates plasmin generation.

plays a key role in the high pathogenicity and infectivity of SARS-CoV-2.

\section{COMPREHENSIVE ROLE OF FIBRINOLYSIS IN COVID-19 PATHOGENICITY: (FIGURE 2)}

SARS-CoV-2 binds with high avidity to the ACE2 receptor. This enzyme exerts a protective function on endothelial cells and pneumocytes, (Tikellis and Thomas, 2012) by virtue of its anti-inflammatory, anti-thrombin and anti-oxidant activity (Pai et al., 2017; Bavishi et al., 2020). A reduction in the protective effects of ACE2, as in aging, diabetes mellitus, and cardiovascular diseases, results in cellular damage and harmful consequences, with increasing oxidative stress and thrombosis (Tikellis and Thomas, 2012). Of note, administering recombinant ACE2 to ACE-deficient mice with induced lung injury protects them from developing an ARDS-like syndrome (Imai et al., 2005). The high mortality in old COVID-19 patients with comorbidities associated with endothelial dysfunction, indicates that this protective effect of ACE2 may be essential for survival (Patel and Verma, 2020; Sunden-Cullberg, 2020). Accordingly, it has been suggested that COVID-19 patients could be treated with human recombinant soluble ACE2 (Batlle et al., 2020; Kruse, 2020). Despite evidence for increased expression of ACE2 in patients with cardiovascular disease who are treated with ACE inhibitors (ACE-I) and angiotensin receptor blockers, the 


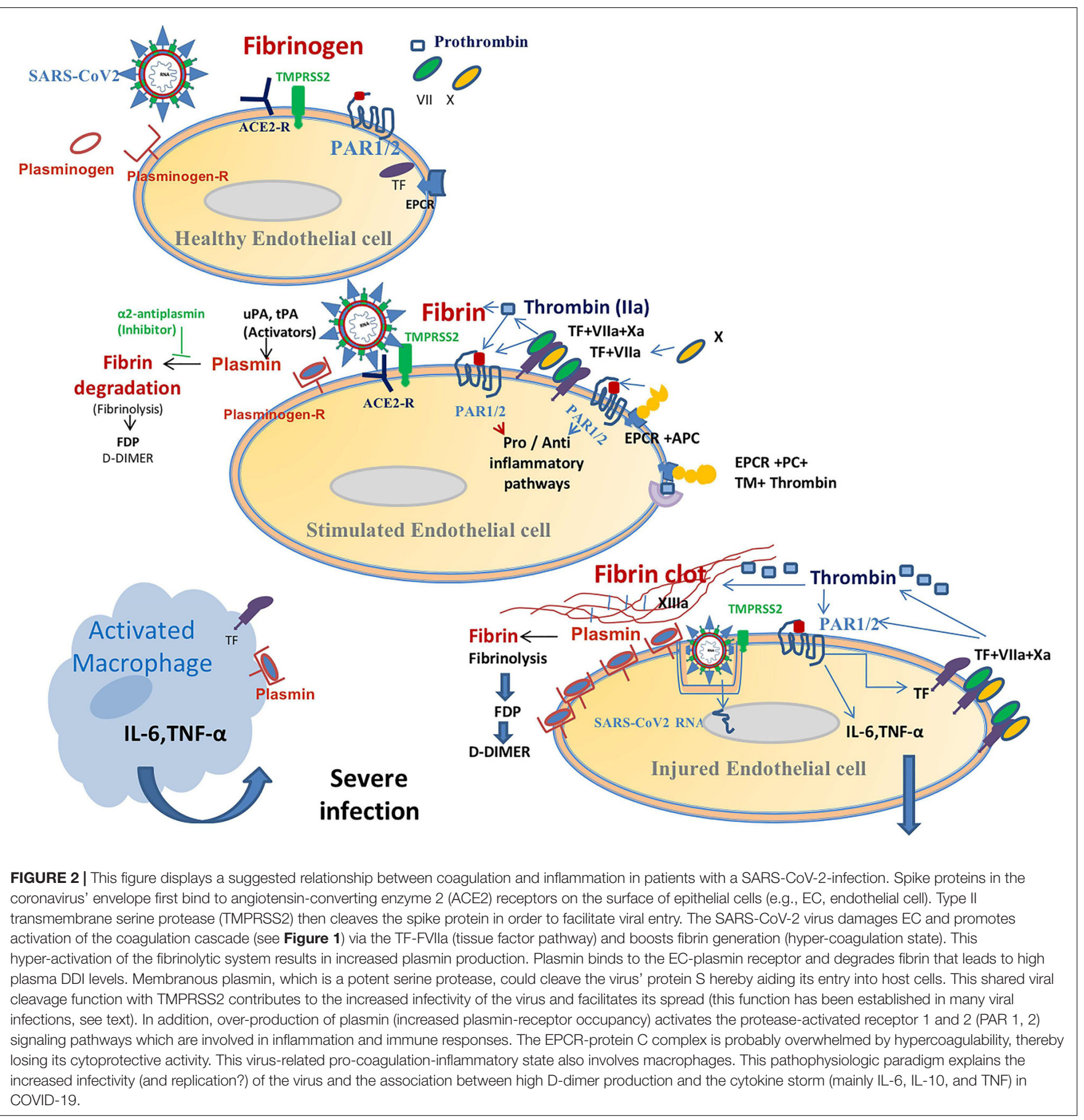

actual impact of these drugs on COVID-19 was reported to be controversial (Danser et al., 2020; Mancia et al., 2020). Of note, ACE-Is have an anti-fibrinolytic effect in humans, (Tiryaki et al., 2010) and recent guidance recommends continuing these drugs in patients with cardiovascular diseases.

Transmembrane serine protease 2 has pivotal role in the infectivity of SARS-CoV-2. The cleavage of the coronavirus' $S$ protein by TMPRSS2 is not exclusive for SARS-CoV-1 and 2 (Hoffmann et al., 2020; Matsuyama et al., 2020). Other viruses enter host cells by utilizing this pathway, such as the influenza
H1N1 and herpes viruses (Hamming et al., 2004; Matsuyama et al., 2020). Results from in vitro studies showed that TMPRSS2 inhibition does not completely block virus entry into host cells (Tang et al., 2020c; Zhang et al., 2020). Camostat mesylate, a potent serine protease inhibitor which efficiently inhibits TMPRSS2, is currently under clinical investigation for reducing the virus infectivity in COVID-19 patients (Kawase et al., 2012; Hoffmann et al., 2020).

Although TMPRSS2 is the major enzyme which facilitates the entry of SARS-CoV-2 into the host cell, other serine proteases 
possess this activity (Hoffmann et al., 2020; Walls et al., 2020). The serine proteases, trypsin, elastase and furin, can cleave $S$ protein in the viral envelope of SARS-CoV and MERS-CoV (Ji et al., 2020; Rabi et al., 2020; Tang et al., 2020c). Furin is a part of the trans-Golgi network and is highly expressed on endothelial and pneumocyte cells, and it has been recently reported that it also cleaves SARS-CoV-2 (Braun and Sauter, 2019; Lukassen et al., 2020; Walls et al., 2020). Furin can also cleave the $S$ protein of non-coronaviruses, such as the West Nile, Zika, and respiratory syncytial (RS) viruses (Millet and Whittaker, 2015; Coutard et al., 2020; Lukassen et al., 2020).

Plasmin, which is bound to plasmin-Receptor located on cell membranes (Figure 2), possesses furin-like cleavage activity (Miles et al., 1986; Kam et al., 2009; Zhao et al., 2020). Plasmin's cleavage activity was first described for the influenza H1N1 virus (Goto et al., 2001; Murakami et al., 2001). However, plasmin's cleavage activity (furin-like) on SARS-CoV-2 requires elucidation (Millet and Whittaker, 2015).

Therefore, cell entry of the virus depends on the specific binding to ACE2 and cleavage by TMPRSS2, but this latter step can be replaced by other serine proteases, such as plasmin (Kawase et al., 2012; Hoffmann et al., 2020; Zhang et al., 2020).

Findings from autopsies of severely affected COVID-19 patients include the presence of abundance of fibrin deposition, (Fox et al., 2020) which requires increased plasmin activity. In addition to its cleavage activity on viruses, plasmin can activate human macrophages promoting production of pro-inflammatory cytokines, such as IL-6, IL-8, IL-10, and TNF (Li et al., 2007). An increased plasma IL-6 level is a marker of the "cytokine release syndrome" in COVID-19 and is associated with poor outcome (Henry et al., 2020). To summarize thus far, high plasmin activity could participate in the perpetuity of virus infectivity and contribute to the excessive inflammatory and immune responses in COVID-19.

Acute respiratory distress syndrome is the most challenging clinical finding and the leading cause of death in patients with COVID-19-associated pneumonia (Wu et al., 2020). The pneumocytes and endothelial cells in the pulmonary alveoli share similar protective biologic mechanisms (Tikellis and Thomas, 2012; Nova et al., 2019). Some patients with COVID-19 present in a procoagulant state with a catastrophic microvascular injury in their lungs (Fox et al., 2020; Magro et al., 2020). The coronaviruses, MERS-CoV, SARS-CoV, and SARS-CoV-2, target cells with high expression of ACE2 and TMPRSS2, such as endothelial cells and pneumocytes (Glowacka et al., 2011). ACE2 has an important protective function in these cells. The lung injury in SARS is reported to be dependent on the balance between coagulation activity and the extent of fibrinolytic process (Gralinski et al., 2013). It is also known that plasminogenplasmin activity is increased in ARDS (Spadaro et al., 2019). The levels of procoagulant components, in the bronchoalveolar lavage of patients with ARDS, such as plasmin and fibrinolytic degradation products, are markedly higher than in those without ARDS (Fuchs-Buder et al., 1996). A suggestion for the role of the fibrinolytic system in the genesis of ARDS in COVID-19 patients, (Idell, 2003; Spadaro et al., 2019) is supported by a the results of an investigation in plasminogen activator inhibitor-1
(PAI-1) deficient mice. The results indicate that the tPA and uPA contribute to the development the lung injury in coronaviruses infection, and PAI has a protective function in this condition (Gralinski et al., 2013). This suggest that "partial" inhibition of the hyper-fibrinolytic process in COVID-19 might mitigate the development of ARDS. An activated coagulation-plasmin-fibrin pathway in ARDS triggers a various protease secretion, such as elastase, and strong cytokine response, which is manifested by activated leukocytes and macrophages (Gralinski et al., 2013; Spadaro et al., 2019). The cytokine release syndrome has not yet been fully characterized in patients with COVID-19 (Pedersen and Ho, 2020). However, there is evidence that the high viral load in the lungs of COVID-19 patients is associated with an acute inflammatory response comprising epithelial cells and activated macrophages, which are largely responsible for the secretion of the cytokines, such as TNF, IL-6, IL-8, IL-1 $\beta$, and CXCL10 (Freeman and Swartz, 2020).

\section{Virus-Related Coagulation-Inflammation Interaction}

Viruses affect the hemostatic system via activation/deactivation of platelet aggregation, coagulation, and fibrinolysis (Goeijenbier et al., 2012; Koupenova et al., 2018). There is an increasing body of evidence which shows that a viral infection orchestrates a collaborative process which connects coagulation with the inflammatory response (Goeijenbier et al., 2012). Viral infection elicits an inflammatory reaction, which in turn activates the coagulation system (Opal, 2003). Frequently, viral-related hemostasis elicits a procoagulant-thrombotic effect, such as that seen in cytomegalovirus, hepatitis C and HIV infections (van Dam-Mieras et al., 1992; Chiappetta et al., 2016). In contrast, ebola, dengue, and other hemorrhagic viruses, which can also cause endothelial damage, are associated with increased anticoagulant effects and fatal hemorrhage (Schnittler et al., 1993; Mahanty and Bray, 2004). Viruses which damage endothelial cells can promote the generation of the TF-VIIa-Xa-EPCR complex (procoagulant path, Figures 1, 2), which is able to activate PAR2 and trigger an innate immune response (Zelaya et al., 2018). During viral infection, PAR2 activation provokes the toll-like receptor 4 (TLR 4) to modulate the inflammatory response (Antoniak and Mackman, 2014). On the other hand, some viral infections can increase thrombin production and activate the EPCR-aPC complex, which in turn stimulates PAR1 signaling to exert a cytoprotective effect (Mosnier et al., 2007; Antoniak and Mackman, 2014).

In summary, the resultant coagulation abnormalities in viral infections depends on the effect of the virus on the balance between the pro- and anti-coagulant pathways. A virus which mainly activates the procoagulant and fibrinolytic systems could induce in a severe inflammatory response. A virus which activate the anti-coagulant pathway i.e., could induce a mild inflammatory response (Mosnier et al., 2007; Antoniak and Mackman, 2014; Nieman, 2016).

For example, patients with dengue hemorrhagic fever produce antibodies against the virus, which can activate plasminogen and fibrinolysis and contributes to bleeding 
diathesis (Chuang et al., 2016). In contrast, SARS-CoV-2 causes hyper-fibrinolysis without any significant bleeding (Chen et al., 2020; Han et al., 2020).

\section{Overview of COVID-19 Treatment}

Although several therapeutic agents have been evaluated for the treatment of COVID-19, none have yet been shown to be efficacious (Sanders et al., 2020). The similarity in clinical features of coronaviruses infections offers therapeutic modalities based on SARS and MERS epidemics to clinicians. However, results on the efficacy of reported treatments in SARS and MERS are controversial (Stockman et al., 2006; Morra et al., 2018).

Lopinavir-ritonavir, an aspartate protease inhibitor combined with a CYP450 inhibitor for increasing its half-life, is reported as having no beneficial effects in COVID-19 patients (Cao et al., 2020). Ribavirin, a nucleotide analog, which blocks the viral RNA-dependent RNA polymerase, is also reported as having no beneficial effect (Morra et al., 2018). Remdisivir, a potent RNA polymerase inhibitor and whose use was compassionate, is reported to be effective in shortening the time to recovery in COVID-19 patients (Gordon et al., 2020; Grein et al., 2020).

The antimalarial drugs, chloroquine and hydroxychloroquine, which inhibit lysosomal activity and autophagy, have beneficial immunomodulatory effects (Schrezenmeier and Dorner, 2020). Hydroxychloroquine blocks the endosomal entry of SARS-CoV2 into host cells and reduces cytokine production in vitro (Sinha and Balayla, 2020). Moreover, it has been reported that hydroxychloroquine (a) is not effective in preventing the development of COVID-19 after a moderate to high-risk exposure in out-patients and (b) does not affect the course of the disease in hospitalized patients (Boulware et al., 2020; Cavalcanti et al., 2020; Gautret et al., 2020; Geleris et al., 2020; Vanden Eynde, 2020).

The presence of high plasma IL-6 levels in COVID-19 patients may justify the use of tocilizumab, a monoclonal IL-6 receptor antibody, and offer a protective effect against the cytokine storm. However, its effect on virus replication and infectivity is doubtful (Biran et al., 2020; Buonaguro et al., 2020; Price et al., 2020). More recently, Japanese authors suggested treating COVID19 patients with heparin and nafamostat mesylate, a synthetic serine protease inhibitor, which possesses anti-trypsin and antifibrinolytic effects (Asakura and Ogawa, 2020). Nafamostat is also being investigated because of ability to block MERS-CoV entry into host cells (Yamamoto et al., 2016).

\section{Mechanism-Based Proposed Treatment: (see Figure 2)}

In light of the present need, it enables the use of an unconventional treatment for COVID-19 patients. Since a procoagulant state and hyper-fibrinolysis co-exist in COVID-19 (Tang et al., 2020b), we assume that the increased fibrinolysis boosts the infectivity of SARS-CoV-2 via the plasmin-mediated pathway. In addition, plasmin elicits a pro-inflammatory response by activating macrophages (releasing IL-6, and TNF) and increases PAR2-TLR4 signaling (Li et al., 2007; Antoniak and Mackman, 2014). Moreover, the increased mortality in COVID-19 is associated with conditions, which are associated with endothelial dysfunction, low ACE2 expression, and high circulating plasminogen levels (Tikellis and Thomas, 2012; Derhaschnig et al., 2013).

We suggest that pharmacologic interventions whose aim is to reduce plasmin production may decrease virus infectivity and attenuate the associated inflammatory condition in COVID19 patients.

Tranexamic acid (TA) competitively inhibits the activation of plasminogen (via binding to the kringle domain), thereby reducing the conversion of plasminogen to plasmin, which in turn results in lowering circulating DDI levels. TA is used to treat individuals with bleeding diathesis and can be administered, intravenously, orally, or locally. It can also be administered by inhalation to control pulmonary hemorrhage. TA's half-life is $\sim 2$ $3 \mathrm{~h}$, and is mainly eliminated in urine (McCormack, 2012). The efficacy of the inhaled route of administration has been tested in patients with hemoptysis. The investigators reported that inhaled TA was effective and safe for hemoptysis resolution (Wand et al., 2018). Similar results were obtained in patients with hemoptysis who were treated with oral or intravenous TA (Solomonov et al., 2009; Prutsky et al., 2016).

Tranexamic acid is well tolerated and the occurrence of adverse effects, such as mild to moderate headache, muscle cramp and arthralgia, nausea, and diarrhea, are uncommon (Freeman et al., 2011). While inhibition of fibrinolysis could increase thrombotic risk, there is no reported evidence for thromboembolism with the use of TA.

For the past two decades, TA has been used in combination with prophylactic anticoagulation (low dose warfarin, LMWH, and DOACs) in elderly patients undergoing major orthopedic surgery with high risk for thrombosis and hemorrhage (Wang et al., 2018; Tang et al., 2019). This combined therapeutic modality offers anticoagulant, anti-fibrinolytic and antiinflammatory effects, thereby reducing thrombosis, bleeding and indices of inflammation (Gillette et al., 2013; Karampinas et al., 2019). Hence, our suggestion is to use TA to treat patients with moderate to severe COVID-19-associated pneumonia. TA could be administered through a systemic route or by using a closed-nebulizer (Wand et al., 2018). All COVID-19 patients should receive intensification of anticoagulant dosing (Barnes et al., 2020; Thachil et al., 2020; Zhai et al., 2020).

The thrombotic burden in COVID-19 patients increases with disease severity. Thus, the suggested intervention with TA should exclude critically ill patients. Future studies should address the timing of the intervention in light of the emerging data on SARSCoV-2 dynamics and COVID-19 features (Sun et al., 2020; Zheng et al., 2020).

Administering alpha 2-antiplasmin (alpha 2-AP) is an alternative treatment to alleviate the respiratory distress of COVID-19 patients. Alpha 2-AP is a potent plasmin scavenger and is usually used as alpha 2-AP replacement therapy for patients with a homozygous alpha 2-AP deficiency. These patients are hemophilia-like and tend to bleed mainly after surgery and alpha 2-AP replacement therapy is the only efficient treatment for these patients (Saes et al., 2018). Therefore, this treatment should be reserved for those critically ill COVID-19 patients with low plasma alpha 2-AP levels. 


\section{SUMMARY}

This proposed mechanisms and treatment modality are founded on a comprehensive review of reported investigations on the interactions between the coagulation-fibrinolysis and inflammation pathways in coronaviruses diseases. The severity of COVID-19-associated pneumonia places the patient at risk for irreversible ARDS and death. A balanced assessment of the risk-benefit ratio in a deteriorating patient with COVID-19 sometimes requires the implementation of an out-of-the-box treatment in the absence of an alternative proven treatment.

\section{REFERENCES}

Antoniak, S., and Mackman, N. (2014). Multiple roles of the coagulation protease cascade during virus infection. Blood 123, 2605-2613. doi: 10.1182/blood-201309-526277

Arneth, B. (2019). Coevolution of the coagulation and immune systems. Inflamm. Res. 68, 117-123. doi: 10.1007/s00011-018-01210-y

Asakura, H., and Ogawa, H. (2020). Potential of heparin and nafamostat combination therapy for COVID-19. J. Thromb. Haemost. 18, 1521-1522. doi: $10.1111 /$ jth. 14858

Barnes, G. D., Burnett, A., Allen, A., Blumenstein, M., Clark, N. P., Cuker, A., et al. (2020). Thromboembolism and anticoagulant therapy during the COVID-19 pandemic: interim clinical guidance from the anticoagulation forum. J. Thromb. Thrombolysis 50, 72-81. doi: 10.1007/s11239-020-02138-z

Batlle, D., Wysocki, J., and Satchell, K. (2020). Soluble angiotensin-converting enzyme 2: a potential approach for coronavirus infection therapy? Clin. Sci. 134, 543-545. doi: 10.1042/CS20200163

Bavishi, C., Maddox, T. M., and Messerli, F. H. (2020). Coronavirus Disease 2019 (COVID-19) infection and renin angiotensin system blockers. JAMA Cardiol. 5, 745-747. doi: 10.1001/jamacardio.2020.1282

Biran, N., Ip, A., Ahn, J., Go, R. C., Wang, S., Mathura, S., et al. (2020). Tocilizumab among patients with COVID-19 in the intensive care unit: a multicentre observational study. Lancet Rheumatol. 2, e603-e612. doi: 10.1016/S26659913(20)30277-0

Boulware, D. R., Pullen, M. F., Bangdiwala, A. S., Pastick, K. A., Lofgren, S. M., Okafor, E. C., et al. (2020). A randomized trial of hydroxychloroquine as postexposure prophylaxis for COVID-19. N. Engl. J. Med. 383, 517-525. doi: 10.1056/NEJMoa2016638

Braun, E., and Sauter, D. (2019). Furin-mediated protein processing in infectious diseases and cancer. Clin. Transl. Immunol. 8, e1073. doi: 10.1002/cti2.1073

Buonaguro, F. M., Puzanov, I., and Ascierto, P. A. (2020). Anti-Il6R role in treatment of COVID-19-related Ards. J. Transl. Med. 18:165. doi: 10.1186/ s12967-020-02333-9

Cao, B., Wang, Y., Wen, D., Liu, W., Wang, J., Fan, G., et al. (2020). A trial of Lopinavir-Ritonavir in adults hospitalized with severe COVID-19. N. Engl. J. Med. 382, 1787-1799. doi: 10.1056/NEJMoa2001282

Cavalcanti, A. B., Zampieri, F. G., Rosa, R. G., Azevedo, L. C. P., Veiga, V. C., Avezum, A., et al. (2020). Hydroxychloroquine with or without Azithromycin in Mild-to-Moderate COVID-19. N Engl J Med. 383, 2041-2052. doi: 10.1056/ NEJMoa2019014

Chen, N., Zhou, M., Dong, X., Qu, J., Gong, F., Han, Y., et al. (2020). Epidemiological and clinical characteristics of 99 cases of 2019 novel coronavirus pneumonia in Wuhan, China: a descriptive study. Lancet 395, 507-513. doi: 10.1016/S0140-6736(20)30211-7

Chiappetta, S., Ripa, M., Galli, L., Razzari, C., Longo, V., Galli, A., et al. (2016) Soluble endothelial protein $\mathrm{C}$ receptor (sepcr) as an inflammatory biomarker in naive Hiv-infected patients during Art. J. Antimicrob. Chemother. 71, 16271631. doi: 10.1093/jac/dkw010

Chuang, Y. C., Lin, J., Lin, Y. S., Wang, S., and Yeh, T. M. (2016). Dengue virus nonstructural protein 1 -induced antibodies cross-react with human

\section{AUTHOR CONTRIBUTIONS}

GJ: idea design and writing. AA: protein C expert and consultant. $\mathrm{BB}$ : writing and consultant as world expert in homeostasis. All authors contributed to the article and approved the submitted version.

\section{FUNDING}

This work was funded by the Yahel Foundation and Recanati Research Center.

plasminogen and enhance its activation. J. Immunol. 196, 1218-1226. doi: 10. 4049/jimmunol.1500057

Coutard, B., Valle, C., De Lamballerie, X., Canard, B., Seidah, N. G., and Decroly, E. (2020). The spike glycoprotein of the new coronavirus 2019-nCoV contains a furin-like cleavage site absent in $\mathrm{CoV}$ of the same clade. Antiviral Res. 176:104742.

Danser, A. H. J., Epstein, M., and Batlle, D. (2020). Renin-angiotensin system blockers and the COVID-19 pandemic: at present there is no evidence to abandon renin-angiotensin system blockers. Hypertension 75, 1382-1385. doi: 10.1161/HYPERTENSIONAHA.120.15082

Derhaschnig, U., Testori, C., Riedmueller, E., Aschauer, S., Wolzt, M., and Jilma, B. (2013). Hypertensive emergencies are associated with elevated markers of inflammation, coagulation, platelet activation and fibrinolysis. J. Hum. Hypertens 27, 368-373. doi: 10.1038/jhh.2012.53

Ducros, E., Mirshahi, S. S., Faussat, A. M., Mirshahi, P., Dimicoli, S., Tang, R., et al. (2012). Soluble endothelial protein C receptor (sepcr) is likely a biomarker of cancer-associated hypercoagulability in human hematologic malignancies. Cancer Med 1, 261-267. doi: 10.1002/cam4.11

Fox, S. E., Akmatbekov, A., Harbert, J. L., Li, G., Brown, J. Q., and Vander Heide, R. S. (2020). Pulmonary and cardiac pathology in COVID-19: the first autopsy series from new Orleans. medRxivn [Preprint]. doi: 10.1101/2020.04. 06.20050575

Freeman, E. W., Lukes, A., Vandrie, D., Mabey, R. G., Gersten, J., and Adomako, T. L. (2011). A dose-response study of a novel, oral tranexamic formulation for heavy menstrual bleeding. Am. J. Obstet. Gynecol. 205:319.e1-7. doi: 10.1016/j. ajog.2011.05.015

Freeman, T. L., and Swartz, T. H. (2020). Targeting the NLRP3 Inflammasome in Severe COVID-19. Front. Immunol. 11:1518. doi: 10.3389/fimmu.2020.01518

Fuchs-Buder, T., De Moerloose, P., Ricou, B., Reber, G., Vifian, C., Nicod, L., et al. (1996). Time course of procoagulant activity and D dimer in bronchoalveolar fluid of patients at risk for or with acute respiratory distress syndrome. Am. J. Respir. Crit. Care Med. 153, 163-167. doi: 10.1164/ajrccm.153.1.8542111

Gautret, P., Lagier, J. C., Parola, P., Hoang, V. T., Meddeb, L., Mailhe, M., et al. (2020). Hydroxychloroquine and azithromycin as a treatment of COVID-19: results of an open-label non-randomized clinical trial. Int. J. Antimicrob. Agents 56:105949. doi: 10.1016/j.ijantimicag.2020.105949

Geleris, J., Sun, Y., Platt, J., Zucker, J., Baldwin, M., Hripcsak, G., et al. (2020). Observational study of hydroxychloroquine in hospitalized patients with COVID-19. N. Engl. J. Med. 382, 2411-2418. doi: 10.1056/NEJMoa2012410

Gillette, B. P., Desimone, L. J., Trousdale, R. T., Pagnano, M. W., and Sierra, R. J. (2013). Low risk of thromboembolic complications with tranexamic acid after primary total hip and knee arthroplasty. Clin. Orthop. Relat. Res. 471, 150-154. doi: 10.1007/s11999-012-2488-z

Glowacka, I., Bertram, S., Müller, M. A., Allen, P., Soilleux, E., Pfefferle, S., et al. (2011). Evidence that Tmprss 3 acitaves the severs respiratory syndrome coronavirus soike protein for membrane fusion and reduces viral control by the humoral immune response. J Virol. 85, 4122-4134. doi: 10.1128/JVI.02232-10

Goeijenbier, M., Van Wissen, M., Van De Weg, C., Jong, E., Gerdes, V. E., Meijers, J. C., et al. (2012). Review: viral infections and mechanisms of thrombosis and bleeding. J. Med. Virol. 84, 1680-1696. doi: 10.1002/jmv.23354 
Gordon, C. J., Tchesnokov, E. P., Woolner, E., Perry, J. K., Feng, J. Y., Porter, D. P., et al. (2020). Remdesivir is a direct-acting antiviral that inhibits Rna-dependent Rna polymerase from severe acute respiratory syndrome coronavirus 2 with high potency. J. Biol. Chem. 295, 6785-6797. doi: 10.1074/jbc.RA120.013679

Goto, H., Wells, K., Takada, A., and Kawaoka, Y. (2001). Plasminogen-binding activity of neuraminidase determines the pathogenicity of influenza A virus. J. Virol. 75, 9297-9301. doi: 10.1128/JVI.75.19.9297-9301.2001

Gralinski, L. E., Bankhead, A. III, Jeng, S., Menachery, V. D., Proll, S., Belisle, S. E., et al. (2013). Mechanisms of severe acute respiratory syndrome coronavirusinduced acute lung injury. $m$ Bio 4, e271-e213. doi: 10.1128/mBio.00271-13

Grasselli, G., Zangrillo, A., Zanella, A., Antonelli, M., Cabrini, L., Castelli, A., et al. (2020). Baseline characteristics and outcomes of 1591 patients infected with SARS-CoV-2 admitted to icus of the lombardy region, Italy. JAMA 323, 1574-1581. doi: 10.1001/jama.2020.5394

Grein, J., Ohmagari, N., Shin, D., Diaz, G., Asperges, E., Castagna, A., et al. (2020). Compassionate use of remdesivir for patients with severe COVID-19. N. Engl. J. Med. 382, 2327-2336. doi: 10.1056/NEJMoa2007016

Guan, W. J., Ni, Z. Y., Hu, Y., Liang, W. H., Ou, C. Q., He, J. X., et al. (2020). Clinical characteristics of Coronavirus Disease 2019 in China. N. Engl. J. Med. 382, 1708-1720. doi: 10.1056/NEJMoa2002032

Hamming, I., Timens, W., Bulthuis, M. L., Lely, A. T., Navis, G., and Van Goor, H. (2004). Tissue distribution of ACE2 protein, the functional receptor for SARS coronavirus. A first step in understanding SARS pathogenesis. J. Pathol. 203, 631-637. doi: 10.1002/path.1570

Han, H., Yang, L., Liu, R., Liu, F., Wu, K. L., Li, J., et al. (2020). Prominent changes in blood coagulation of patients with SARS-CoV-2 infection. Clin. Chem. Lab. Med. 58, 1116-1120. doi: 10.1515/cclm-2020-0188

Hardaway, R. M., Williams, C. H., Marvasti, M., Farias, M., Tseng, A., Pinon, I., et al. (1990). Prevention of adult respiratory distress syndrome with plasminogen activator in pigs. Crit. Care Med. 18, 1413-1418. doi: 10.1097/ 00003246-199012000-00021

Henry, B. M., De Oliveira, M. H. S., Benoit, S., Plebani, M., and Lippi, G. (2020). Hematologic, biochemical and immune biomarker abnormalities associated with severe illness and mortality in coronavirus disease 2019 (COVID-19): a meta-analysis. Clin. Chem. Lab. Med. 58, 1021-1028. doi: 10.1515/cclm-20200369

Hoffmann, M., Kleine-Weber, H., Schroeder, S., Kruger, N., Herrler, T., Erichsen, S., et al. (2020). SARS-CoV-2 cell entry depends on ACE2 and TMPRSS2 and is blocked by a clinically proven protease inhibitor. Cell 181, 271.e8-280.e8. doi: 10.1016/j.cell.2020.02.052

Huang, C., Wang, Y., Li, X., Ren, L., Zhao, J., Hu, Y., et al. (2020). Clinical features of patients infected with 2019 novel coronavirus in Wuhan. China. Lancet 395, 497-506. doi: 10.1016/S0140-6736(20)30183-5

Iba, T., and Levy, J. H. (2018). Inflammation and thrombosis: roles of neutrophils, platelets and endothelial cells and their interactions in thrombus formation during sepsis. J. Thromb. Haemost. 16, 231-241. doi: 10.1111/jth.13911

Iba, T., Nisio, M. D., Levy, J. H., Kitamura, N., and Thachil, J. (2017). New criteria for sepsis-induced coagulopathy (Sic) following the revised sepsis definition: a retrospective analysis of a nationwide survey. BMJ Open 7:e017046. doi: 10.1136/bmjopen-2017-017046

Idell, S. (2003). Coagulation, fibrinolysis, and fibrin deposition in acute lung injury. Crit. Care Med. 31, S213-S220. doi: 10.1097/01.CCM.0000057846.21303.AB

Imai, Y., Kuba, K., Rao, S., Huan, Y., Guo, F., Guan, B., et al. (2005). Angiotensinconverting enzyme 2 protects from severe acute lung failure. Nature 436, 112-116. doi: 10.1038/nature03712

Ji, H. L., Zhao, R., Matalon, S., and Matthay, M. A. (2020). Elevated Plasmin(ogen) as a common risk factor for COVID-19 susceptibility. Physiol. Rev. 100, 10651075. doi: 10.1152/physrev.00013.2020

Kam, Y. W., Okumura, Y., Kido, H., Ng, L. F., Bruzzone, R., and Altmeyer, R. (2009). Cleavage of the SARS coronavirus spike glycoprotein by airway proteases enhances virus entry into human bronchial epithelial cells in vitro. PLoS One 4:e7870. doi: 10.1371/journal.pone.0007870

Karampinas, P. K., Megaloikonomos, P. D., Lampropoulou-Adamidou, K., Papadelis, E. G., Mavrogenis, A. F., Vlamis, J. A., et al. (2019). Similar thromboprophylaxis with rivaroxaban and low molecular weight heparin but fewer hemorrhagic complications with combined intra-articular and intravenous tranexamic acid in total knee arthroplasty. Eur. J. Orthop. Surg. Traumatol. 29, 455-460. doi: 10.1007/s00590-018-2307-7
Kawase, M., Shirato, K., Van Der Hoek, L., Taguchi, F., and Matsuyama, S. (2012). Simultaneous treatment of human bronchial epithelial cells with serine and cysteine protease inhibitors prevents severe acute respiratory syndrome coronavirus entry. J. Virol. 86, 6537-6545. doi: 10.1128/JVI.00094-12

Klok, F. A., Kruip, M. J. H. A., van der Meer, N. J. M., Arbous, M. S., Gommers, D. A. M. P. J., Kant, K. M., et al. (2020). Incidence of thrombotic complications in critically ill ICU patients with COVID-19. Thromb. Res. 191, 145-147. doi: 10.1016/j.thromres.2020.04.013

Kollias, A., Kyriakoulis, K. G., Dimakakos, E., Poulakou, G., Stergiou, G. S., and Syrigos, K. (2020). Thromboembolic risk and anticoagulant therapy in COVID-19 patients: emerging evidence and call for action. Br. J. Haematol. 189, 846-847. doi: 10.1111/bjh.16727

Koupenova, M., Clancy, L., Corkrey, H. A., and Freedman, J. E. (2018). Circulating platelets as mediators of immunity, inflammation, and thrombosis. Circ. Res. 122, 337-351. doi: 10.1161/CIRCRESAHA.117.310795

Kruse, R. L. (2020). Therapeutic strategies in an outbreak scenario to treat the novel coronavirus originating in Wuhan, China. F1000Res 9:72.

Li, Q., Guan, X., Wu, P., Wang, X., Zhou, L., Tong, Y., et al. (2020). Early transmission dynamics in Wuhan, China, of novel coronavirus-infected pneumonia. N. Engl. J. Med. 382, 1199-1207. doi: 10.1056/NEJMoa2001316

Li, Q., Laumonnier, Y., Syrovets, T., and Simmet, T. (2007). Plasmin triggers cytokine induction in human monocyte-derived macrophages. Arterioscler. Thromb. Vasc. Biol. 27, 1383-1389. doi: 10.1161/ATVBAHA.107.142901

Liu, C., Ma, Y., Su, Z., Zhao, R., Zhao, X., Nie, H. G., et al. (2018). Meta-analysis of preclinical studies of fibrinolytic therapy for acute lung injury. Front. Immunol. 9:1898. doi: 10.3389/fimmu.2018.01898

Lukassen, S., Lorenz Chua, R., Trefzer, T., Kahn, N. C., Schneider, M. A., Muley, T., et al. (2020). SARS-CoV-2 receptor ACE2 and TMPRSS2 are primarily expressed in bronchial transient secretory cells. Embo. J. 39:e105114. doi: 10. 15252/embj.2020105114

Magro, C., Mulvey, J. J., Berlin, D., Nuovo, G., Salvatore, S., Harp, J., et al. (2020). Complement associated microvascular injury and thrombosis in the pathogenesis of severe COVID-19 infection: a report of five cases. Transl. Res. 220, 1-13. doi: 10.1016/j.trsl.2020.04.007

Mahanty, S., and Bray, M. (2004). Pathogenesis of filoviral haemorrhagic fevers. Lancet Infect. Dis. 4, 487-498. doi: 10.1016/S1473-3099(04)01103-X

Mancia, G., Rea, F., Ludergnani, M., Apolone, G., and Corrao, G. (2020). Reninangiotensin-aldosterone system blockers and the risk of COVID-19. N. Engl. J. Med. 382, 2431-2440. doi: 10.1056/NEJMoa2006923

Matsuyama, S., Nao, N., Shirato, K., Kawase, M., Saito, S., Takayama, I., et al. (2020). Enhanced isolation of SARS-CoV-2 by TMPRSS2-expressing cells. Proc. Natl. Acad. Sci. U.S.A. 117, 7001-7003. doi: 10.1073/pnas.2002589117

McCormack, P. L. (2012). Tranexamic acid: a review of its use in the treatment of hyperfibrinolysis. Drugs 72, 585-617. doi: 10.2165/11209070-000000000-00000

Miles, L. A., Ginsberg, M. H., White, J. G., and Plow, E. F. (1986). Plasminogen interacts with human platelets through two distinct mechanisms. J. Clin. Invest. 77, 2001-2009. doi: 10.1172/JCI112529

Millet, J. K., and Whittaker, G. R. (2015). Host cell proteases: critical determinants of coronavirus tropism and pathogenesis. Virus Res. 202, 120-134. doi: 10.1016/ j.virusres.2014.11.021

Mohan Rao, L. V., Esmon, C. T., and Pendurthi, U. R. (2014). Endothelial cell protein C receptor: a multiliganded and multifunctional receptor. Blood 124, 1553-1562. doi: 10.1182/blood-2014-05-578328

Montagnana, M., Lippi, G., and Danese, E. (2017). An overview of thrombophilia and associated laboratory testing. Methods Mol. Biol. 1646, 113-135. doi: 10. 1007/978-1-4939-7196-1_9

Morra, M. E., Van Thanh, L., Kamel, M. G., Ghazy, A. A., Altibi, A. M. A., Dat, L. M., et al. (2018). Clinical outcomes of current medical approaches for Middle East respiratory syndrome: a systematic review and meta-analysis. Rev. Med. Virol. 28:e1977. doi: 10.1002/rmv.1977

Mosnier, L. O., Zlokovic, B. V., and Griffin, J. H. (2007). The cytoprotective protein C pathway. Blood 109, 3161-3172. doi: 10.1182/blood-2006-09-003004

Murakami, M., Towatari, T., Ohuchi, M., Shiota, M., Akao, M., Okumura, Y., et al. (2001). Mini-plasmin found in the epithelial cells of bronchioles triggers infection by broad-spectrum influenza A viruses and Sendai virus. Eur. J. Biochem. 268, 2847-2855. doi: 10.1046/j.1432-1327.2001.02166.x

Nieman, M. T. (2016). Protease-activated receptors in hemostasis. Blood 128, 169-177. doi: 10.1182/blood-2015-11-636472 
Nova, Z., Skovierova, H., and Calkovska, A. (2019). Alveolar-capillary membranerelated pulmonary cells as a target in endotoxin-induced acute lung injury. Int. J. Mol. Sci. 20:831. doi: 10.3390/ijms20040831

Olson, J. D. (2015). D-dimer: an overview of hemostasis and fibrinolysis, assays, and clinical applications. Adv. Clin. Chem. 69, 1-46. doi: 10.1016/bs.acc.2014. 12.001

Ong, S. W. X., Tan, Y. K., Chia, P. Y., Lee, T. H., Ng, O. T., Wong, M. S. Y., et al. (2020). Air, surface environmental, and personal protective equipment contamination by severe acute respiratory syndrome Coronavirus 2 (SARSCoV-2) from a symptomatic patient. JAMA 323, 1610-1612. doi: 10.1001/jama. 2020.3227

Opal, S. M. (2003). Interactions between coagulation and inflammation. Scand. J. Infect. Dis. 35, 545-554. doi: 10.1080/00365540310015638

Pai, W. Y., Lo, W. Y., Hsu, T., Peng, C. T., and Wang, H. J. (2017). Angiotensin(1-7) inhibits thrombin-induced endothelial phenotypic changes and reactive oxygen species production via nadph oxidase 5 downregulation. Front. Physiol. 8:994. doi: 10.3389/fphys.2017.00994

Palta, S., Saroa, R., and Palta, A. (2014). Overview of the coagulation system. Indian J. Anaesth 58, 515-523. doi: 10.4103/0019-5049.144643

Pan, Y., Zhang, D., Yang, P., Poon, L. L. M., and Wang, Q. (2020). Viral load of SARS-CoV-2 in clinical samples. Lancet Infect. Dis. 20, 411-412. doi: 10.1016/ S1473-3099(20)30113-4

Paranjpe, I., Fuster, V., Lala, A., Russak, A. J., Glicksberg, B. S., Levin, M. A., et al. (2020). Association of treatment dose anticoagulation with in-hospital survival among hospitalized patients With COVID-19. J. Am. Coll. Cardiol. 76, 122-124. doi: 10.1016/j.jacc.2020.05.001

Patel, A. B., and Verma, A. (2020). COVID-19 and angiotensin-converting enzyme inhibitors and angiotensin receptor blockers: what is the evidence? JAMA 323, 1769-1770. doi: 10.1001/jama.2020.4812

Pedersen, S. F., and Ho, Y. C. (2020). SARS-CoV-2: a storm is raging. J. Clin. Invest. 130, 2202-2205. doi: 10.1172/JCI137647

Price, C. C., Altice, F. L., Shyr, Y., Koff, A., Pischel, L., Goshua, G., et al. (2020). Tocilizumab treatment for cytokine release syndrome in hospitalized patients with Coronavirus Disease 2019: survival and clinical outcomes. Chest 158, 1397-1408. doi: 10.1016/j.chest.2020.06.006

Prutsky, G., Domecq, J. P., Salazar, C. A., and Accinelli, R. (2016). Antifibrinolytic therapy to reduce haemoptysis from any cause. Cochrane Database Syst. Rev. 11:Cd008711. doi: 10.1002/14651858.CD008711.pub3

Rabi, F. A., Al Zoubi, M. S., Kasasbeh, G. A., Salameh, D. M., and Al-Nasser, A. D. (2020). SARS-CoV-2 and Coronavirus Disease 2019: what we know so far. Pathogens 9:231. doi: 10.3390/pathogens9030231

Saes, J. L., Schols, S. E. M., Van Heerde, W. L., and Nijziel, M. R. (2018). Hemorrhagic disorders of fibrinolysis: a clinical review. J. Thromb. Haemost. doi: 10.1111/jth.14160 [Epub ahead of print].

Sanders, J. M., Monogue, M. L., Jodlowski, T. Z., and Cutrell, J. B. (2020). Pharmacologic treatments for Coronavirus Disease 2019 (COVID-19): a review. JAMA 323, 1824-1836.

Schnittler, H. J., Mahner, F., Drenckhahn, D., Klenk, H. D., and Feldmann, H. (1993). Replication of Marburg virus in human endothelial cells. A possible mechanism for the development of viral hemorrhagic disease. J. Clin. Invest. 91, 1301-1309. doi: 10.1172/JCI116329

Schrezenmeier, E., and Dorner, T. (2020). Mechanisms of action of hydroxychloroquine and chloroquine: implications for rheumatology. Nat. Rev. Rheumatol. 16, 155-166. doi: 10.1038/s41584-020-0372-x

Shi, S., Qin, M., Shen, B., Cai, Y., Liu, T., Yang, F., et al. (2020). Association of cardiac injury with mortality in hospitalized patients with COVID-19 in Wuhan, China. JAMA Cardiol. 5, 802-810. doi: 10.1001/jamacardio.2020.0950

Shirato, K., Nao, N., Katano, H., Takayama, I., Saito, S., Kato, F., et al. (2020). Development of genetic diagnostic methods for novel Coronavirus 2019 (nCoV-2019) in Japan. JPN J. Infect. Dis. 73, 304-307. doi: 10.7883/yoken.JJID. 2020.061

Sinha, N., and Balayla, G. (2020). Hydroxychloroquine and COVID-19. Postgrad. Med. J. 96, 550-555. doi: 10.1136/postgradmedj-2020-137785

Solomonov, A., Fruchter, O., Zuckerman, T., Brenner, B., and Yigla, M. (2009). Pulmonary hemorrhage: a novel mode of therapy. Respir. Med. 103, 1196-1200. doi: 10.1016/j.rmed.2009.02.004

Song, J. C., Wang, G., Zhang, W., Zhang, Y., Li, W. Q., Zhou, Z., et al. (2020). Chinese expert consensus on diagnosis and treatment of coagulation dysfunction in COVID-19. Mil. Med. Res. 7:19. doi: 10.1186/s40779-02000247-7

Spadaro, S., Park, M., Turrini, C., Tunstall, T., Thwaites, R., Mauri, T., et al. (2019). Biomarkers for acute respiratory distress syndrome and prospects for personalised medicine. J. Inflamm. 16;1. doi: 10.1186/s12950-0180202-y

Stockman, L. J., Bellamy, R., and Garner, P. (2006). SARS: systematic review of treatment effects. PLoS Med. 3:e343. doi: 10.1371/journal.pmed.0030343

Sun, J., Tang, X., Bai, R., Liang, C., Zeng, L., Lin, H., et al. (2020). The kinetics of viral load and antibodiesto SARS-CoV-2. Clin. Microbiol. Infect. 26, 1690.e11690.e4. doi: 10.1016/j.cmi.2020.08.043

Sunden-Cullberg, J. (2020). Chronic use of angiotensin-converting enzyme inhibitors and angiotensin ii receptor blockers is high among intensive care unit patients with non-COVID-19 sepsis but carry a moderately increased risk of death. Hypertension 75, e15-e16. doi: 10.1161/HYPERTENSIONAHA.120. 15178

Swieringa, F., Spronk, H. M. H., Heemskerk, J. W. M., and Van Der Meijden, P. E. J. (2018). Integrating platelet and coagulation activation in fibrin clot formation. Res. Pract. Thromb. Haemost. 2, 450-460. doi: 10.1002/rth2. 12107

Tang, N., Bai, H., Chen, X., Gong, J., Li, D., and Sun, Z. (2020a). Anticoagulant treatment is associated with decreased mortality in severe coronavirus disease 2019 patients with coagulopathy. J. Thromb. Haemost. 18, 1520-1521. doi: $10.1111 /$ jth.14851

Tang, N., Li, D., Wang, X., and Sun, Z. (2020b). Abnormal coagulation parameters are associated with poor prognosis in patients with novel coronavirus pneumonia. J. Thromb. Haemost. 18, 844-847. doi: 10.1111/jth. 14768

Tang, T., Bidon, M., Jaimes, J. A., Whittaker, G. R., and Daniel, S. (2020c). Coronavirus membrane fusion mechanism offers as a potential target for antiviral development. Antiviral Res. 178:104792. doi: 10.1016/j.antiviral.2020. 104792

Tang, Y., Wen, Y., Li, W., Li, H., Yang, Y., and Liu, Y. (2019). The efficacy and safety of multiple doses of oral tranexamic acid on blood loss, inflammatory and fibrinolysis response following total knee arthroplasty: a randomized controlled trial. Int. J. Surg. 65, 45-51. doi: 10.1016/j.ijsu.2019.03.011

Thachil, J., Tang, N., Gando, S., Falanga, A., Cattaneo, M., Levi, M., et al. (2020). Isth interim guidance on recognition and management of coagulopathy in COVID-19. J. Thromb. Haemost. 18, 1023-1026. doi: 10.1111/jth.14810

Tikellis, C., and Thomas, M. C. (2012). Angiotensin-converting enzyme 2 (ACE2) is a key modulator of the renin angiotensin system in health and Disease. Int. J. Pept. 2012:256294.

Tiryaki, O., Usalan, C., and Buyukhatipoglu, H. (2010). Effect of combined angiotensin-converting enzyme and aldosterone inhibition on plasma plasminogen activator inhibitor type 1 levels in chronic hypertensive patients. Nephrology 15, 211-215. doi: 10.1111/j.1440-1797.2009.01181.x

van Dam-Mieras, M. C., Muller, A. D., Van Hinsbergh, V. W., Mullers, W. J., Bomans, P. H., and Bruggeman, C. A. (1992). The procoagulant response of cytomegalovirus infected endothelial cells. Thromb. Haemost. 68, 364-370. doi: 10.1055/s-0038-1656381

Vanden Eynde, J. J. (2020). COVID-19: a brief overview of the discovery clinical trial. Pharmaceuticals 13:65. doi: 10.3390/ph13040065

Vatsyayan, R., Kothari, H., Mackman, N., Pendurthi, U. R., and Rao, L. V. (2014). Inactivation of factor Viia by antithrombin in vitro, ex vivo and in vivo: role of tissue factor and endothelial cell protein C receptor. PLoS One 9:e103505. doi: 10.1371/journal.pone.0103505

Walls, A. C., Park, Y. J., Tortorici, M. A., Wall, A., Mcguire, A. T., and Veesler, D. (2020). Structure, function, and antigenicity of the SARSCoV-2 spike glycoprotein. Cell 181, 281.e6-292.e6. doi: 10.1016/j.cell.2020. 02.058

Wand, O., Guber, E., Guber, A., Epstein Shochet, G., Israeli-Shani, L., and Shitrit, D. (2018). Inhaled tranexamic acid for hemoptysis treatment: a randomized controlled trial. Chest 154, 1379-1384. doi: 10.1016/j.chest.2018. 09.026

Wang, D., Hu, B., Hu, C., Zhu, F., Liu, X., Zhang, J., et al. (2020). Clinical characteristics of 138 hospitalized patients with 2019 novel Coronavirusinfected pneumonia in Wuhan, China. JAMA 323, 1061-1069. doi: 10.1001/ jama.2020.1585 
Wang, J., Hajizadeh, N., Moore, E. E., Mcintyre, R. C., Moore, P. K., Veress, L. A., et al. (2020). Tissue plasminogen activator (tpa) treatment for COVID-19 associated acute respiratory distress syndrome (Ards): a case series. J Thromb Haemost. 18, 1752-1755. doi: 10.1111/jth.14828

Wang, D., Luo, Z. Y., Yu, Z. P., Liu, L. X., Chen, C., Meng, W. K., et al. (2018). The antifibrinolytic and anti-inflammatory effects of multiple doses of oral tranexamic acid in total knee arthroplasty patients: a randomized controlled trial. J. Thromb. Haemost. 16, 2442-2453. doi: 10.1111/jth.14316

Whittaker, G. R., and Millet, J. K. (2020). Biochemical characterization of middle east respiratory syndrome coronavirus spike protein proteolytic processing. Methods Mol. Biol. 2099, 21-37. doi: 10.1007/978-1-0716-0211-9_3

Wu, C., Chen, X., Cai, Y., Xia, J., Zhou, X., Xu, S., et al. (2020). Risk factors associated with acute respiratory distress syndrome and death in patients with Coronavirus disease 2019 Pneumonia in Wuhan. China. JAMA Intern Med. 180, 934-943. doi: 10.1001/jamainternmed.2020.0994

Wu, Z., and McGoogan, J. M. (2020). Characteristics of and important lessons from the Coronavirus Disease 2019 (COVID-19) outbreak in China: summary of a report of 72314 cases from the chinese center for disease control and prevention. JAMA 323, 1239-1242. doi: 10.1001/jama.2020.2648

Yamamoto, M., Matsuyama, S., Li, X., Takeda, M., Kawaguchi, Y., Inoue, J. I., et al. (2016). Identification of nafamostat as a potent inhibitor of middle east respiratory syndrome Coronavirus $\mathrm{S}$ protein-mediated membrane fusion using the split-protein-based cell-cell fusion assay. Antimicrob. Agents Chemother. 60, 6532-6539. doi: 10.1128/AAC.01043-16

Yang, X., Yu, Y., Xu, J., Shu, H., Xia, J., Liu, H., et al. (2020). Clinical course and outcomes of critically ill patients with SARS-CoV-2 pneumonia in Wuhan, China: a single-centered, retrospective, observational study. Lancet Respir Med. 8, 475-481. doi: 10.1016/S2213-2600(20)30079-5

Yau, J. W., Teoh, H., and Verma, S. (2015). Endothelial cell control of thrombosis. BMC Cardiovasc Disord. 15:130. doi: 10.1186/s12872-015-0124-z

Yin, S., Huang, M., Li, D., and Tang, N. (2020). Difference of coagulation features between severe pneumonia induced by SARS-CoV2 and non-SARS-CoV2. J. Thromb. Thrombolysis. 3, 1-4. doi: 10.1007/s11239-020-02105-8
Zelaya, H., Rothmeier, A. S., and Ruf, W. (2018). Tissue factor at the crossroad of coagulation and cell signaling. J. Thromb. Haemost. 16, 1941-1952. doi: $10.1111 /$ jth. 14246

Zhai, Z., Li, C., Chen, Y., Gerotziafas, G., Zhang, Z., Wan, J., et al. (2020). Prevention and treatment of venous thromboembolism associated with Coronavirus Disease 2019 infection: a consensus statement before guidelines. Thromb. Haemost. 120, 937-948. doi: 10.1055/s-0040-1710019

Zhang, H., Penninger, J. M., Li, Y., Zhong, N., and Slutsky, A. S. (2020). Angiotensin-converting enzyme 2 (ACE2) as a SARS-CoV-2 receptor: molecular mechanisms and potential therapeutic target. Intensive Care Med. 46, 586-590. doi: 10.1007/s00134-020-05985-9

Zhao, R., Ali, G., Nie, H. G., Chang, Y., Bhattarai, D., Su, X., et al. (2020). Plasmin improves oedematous blood-gas barrier by cleaving epithelial sodium channels. Br. J. Pharmacol. 177, 3091-3106. doi: 10.1111/bph.15038

Zheng, S., Fan, J., Yu, F., Feng, B., Lou, B., Zou, Q., et al. (2020). Viral load dynamics and disease severity in patients infected with SARS-CoV-2 in Zhejiang province, China, January-March 2020: retrospective cohort study. BMJ 369:m1443. doi: 10.1136/bmj.m1443

Zhou, F., Yu, T., Du, R., Fan, G., Liu, Y., Liu, Z., et al. (2020). Clinical course and risk factors for mortality of adult inpatients with COVID-19 in Wuhan, China: a retrospective cohort study. Lancet 395, 1054-1062. doi: 10.1016/ S0140-6736(20)30566-3

Conflict of Interest: The authors declare that the research was conducted in the absence of any commercial or financial relationships that could be construed as a potential conflict of interest.

Copyright (c) 2020 Jacob, Aharon and Brenner. This is an open-access article distributed under the terms of the Creative Commons Attribution License (CC BY). The use, distribution or reproduction in other forums is permitted, provided the original author(s) and the copyright owner(s) are credited and that the original publication in this journal is cited, in accordance with accepted academic practice. No use, distribution or reproduction is permitted which does not comply with these terms. 